\title{
Measurement of the Residual Stresses and Investigation of Their Effects on a Hardfaced Grid Plate due to Thermal Cycling in a Pool Type Sodium-Cooled Fast Reactor
}

\author{
S. Balaguru, ${ }^{1}$ Vela Murali, ${ }^{2}$ and P. Chellapandi ${ }^{3}$ \\ ${ }^{1}$ KCG College of Technology, Karapakkam, Chennai, India \\ ${ }^{2}$ Department of Mechanical Engineering, Anna University, Chennai, India \\ ${ }^{3}$ Nuclear \& Safety Engineering Group, Indira Gandhi Centre for Atomic Research (IGCAR), Kalpakkam, India \\ Correspondence should be addressed to S. Balaguru; balaguru_iit@yahoo.co.in
}

Received 18 November 2015; Accepted 14 February 2016

Academic Editor: Hyeong-Yeon Lee

Copyright ( 92016 S. Balaguru et al. This is an open access article distributed under the Creative Commons Attribution License, which permits unrestricted use, distribution, and reproduction in any medium, provided the original work is properly cited.

\begin{abstract}
In sodium-cooled fast reactors (SFR), grid plate is a critical component which is made of $316 \mathrm{~L}(\mathrm{~N}) \mathrm{SS}$. It is supported on core support structure. The grid plate supports the core subassemblies and maintains their verticality. Most of the components of SFR are made of $316 \mathrm{~L}(\mathrm{~N}) / 304 \mathrm{~L}(\mathrm{~N}) \mathrm{SS}$ and they are in contact with the liquid-metal sodium which acts as a coolant. The peak operating temperature in SFR is $550^{\circ} \mathrm{C}$. However, the self-welding starts at $500^{\circ} \mathrm{C}$. To avoid self-welding and galling, hardfacing of the grid plate has become necessary. Nickel based cobalt-free colmonoy 5 has been identified as the hardfacing material due to its lower dose rate by Plasma Transferred Arc Welding (PTAW). This paper is concerned with the measurement and investigations of the effects of the residual stress generated due to thermal cycling on a scale-down physical model of the grid plate. Finite element analysis of the hardfaced grid plate model is performed for obtaining residual stresses using elastoplastic analysis and hence the results are validated. The effects of the residual stresses due to thermal cycling on the hardfaced grid plate model are studied.
\end{abstract}

\section{Introduction}

Residual stresses can be defined as the stresses that exist within the body of a welded joint or casting, in the absence of external forces or reactions which cause them. Since residual stresses exist without external forces, the resultant force and the resultant moment produced by them must therefore vanish after stress-relieving method. As they remain from previous operations, they are called residual stresses. They are elastic in nature though they result from plastic deformation [1-3]. By dissipating the elastic potential energy stored in the material, residual stresses can be released. But this may also lead to some plastic deformation and new residual stresses. The functional efficiency of component may be affected by the residual stress generated during the welding or hardfacing processes, and it will lead to the failure of structures [4]. Usually, residual stresses may cause cracking as they are the major portions in the stress field. For example, fatigue strength is reduced by tensile residual stress, due to which failure due to fracture would be initiated. The stability limit is reduced by compressive residual stress which reduces the capacity of a member to resist collapsing and buckling [5-8]. The hardfaced deposit on the grid plate of sodium-cooled fast reactor must be able to resist the thermal cycling for reliable operation during the reactor's design life of 40 years. In this present work, the residual stresses generated due to thermal cycling owing to the difference in coefficients of thermal expansion of $316 \mathrm{~L}(\mathrm{~N}) \mathrm{SS}$ (the base metal) and colmonoy (the overlay) are measured and their effects are investigated by fabricating and testing on a scale-down physical model of the grid plate.

Park et al. [9] studied the effects of residual stress by hole drilling method in a lap joint. They predicted that the residual stresses are harmful and they decreased with the welding speed. Sedighi and Mahmoodi [10] measured residual stress in an equal channel angular rolled AI 5083 by the incremental hole drilling method. Makoto et al. [11] evaluated the residual stress near the weld overlay cladding in the reactor pressure 
vessel, using the deep hole drilling (DHD) method. Murugan and Narayanan [12] predicted longitudinal residual stresses, by the three-dimensional transient thermomechanical simulation, using the finite element method on a welded teejoint. Antonov and Kapustin [13] determined the residual stress in butt welding using laser interferometry. Schajer [14] described the advances in residual stress measurement by hole drilling process. Nakacho et al. [15] used inherent strain method for the measurement of residual stresses at the penetration joint of pipe-plate in a reactor vessel. They predicted that the welding residual stresses should be low for the safety of the plant.

\section{Grid Plate in a Nuclear Reactor}

The grid plate is a structure, circular in shape. It is of bolted construction. It not only supports the subassemblies of the core but also provides their verticality even under dynamic load conditions. The grid plate with a core support structure (CSS) assembly is shown in Figure 1(a). The grid plate has two plates, namely, an upper plate and a lower one. These plates are connected by a number of tubes known as sleeves. It consists of an outer shell cylindrical in shape. The upper and lower plates are slit exactly in a similar array of triangular shape, and the sleeves link to the corresponding holes. The subassemblies rest on a hardfaced surface [16]. The bottom of the subassemblies exists inside the sleeve. The grid plate has features to supply sodium through four pipes to the bottom plenum and hence to the cooling system of the main vessel. By proper hardfacing, the dilution effects and also the residual stress can be controlled [17-21]. The bottom of the grid plate assembly after hardfacing is shown in Figure 1(b).

\section{Significance of Work}

The structural integrity of the grid plate is very important. Hence, it is designed as per the latest French Design Code called RCC-MR (2009). However, the code is silent on the residual stress distribution. Hence, it is the designer's responsibility to keep the residual stress at a minimum. And also the effect of the residual stress should be studied in detail. In this work, the effect of the residual stress during thermal cycling between $30^{\circ} \mathrm{C}$ and $550^{\circ} \mathrm{C}$ of hardfaced $316 \mathrm{~L}(\mathrm{~N})$ SS has been studied both experimentally and numerically. The grid plate requires basically 3 different temperatures: $200^{\circ} \mathrm{C}$ at shutdown condition, $400^{\circ} \mathrm{C}$ at normal operating condition, and $550^{\circ} \mathrm{C}$ at peak condition which corresponds to the maximum temperature of liquid sodium that would be encountered. Due to transient condition, the processes are slow in the reactor, and hence the thermal transient effects are not important. Hence, thermal steady state is done. The residual stress evolved due to the thermal cycling owing to the difference in coefficients of thermal expansion of steel and colmonoy is computed in this paper.

\section{Experimental Set-Up}

For the experimental work, a scale-down physical model of grid plate made up of $316 \mathrm{~L}(\mathrm{~N})$ SS with the dimensions shown in Figure 2 was prepared. A trapezoidal annular groove to a depth of $3 \mathrm{~mm}$ was made by milling process to coat colmonoy. $\mathrm{Ni}$ based hardfacing alloy called colmonoy 5 was coated in the annular groove by Plasma Transferred Arc Welding at the welding speed of $3 \mathrm{~mm} / \mathrm{s}$ for the least process-induced residual stresses with minimum dilution from the base metal into the coating so that the properties of the coating are not significantly affected $[22,23]$. The process-induced residual stresses should be low for better annealing results. The top portion of the colmonoy coating was machined to maintain evenness, so that a $3 \mathrm{~mm}$ height of colmonoy lies inside the groove and $1 \mathrm{~mm}$ lies above the surface as shown in Figure 2(b), to support the subassemblies. Colmonoy was coated inside the groove for better deposition and finer dendrites for retaining higher hardness compared to that coated fully on the plane surface [24]. The grid plate model was annealed to remove process-induced residual stress.

The thermal cycle consists of heating the colmonoy surface from room temperature to peak operating temperature of $550^{\circ} \mathrm{C}$ isothermally for 1 hour, by means of electrical resistance heating, and then cooling naturally by removing the heat source to reach room temperature in the next 2 hours. An incremental hole drilling (IHD) strain gauge method is an important and widely accepted method. By using this method, residual stresses were measured quantitatively in elastic and isotropic materials. This method is accurate, versatile, and easy to carry out. Though it is a semidestructive method, the destruction caused by the drilling of hole can be repaired as the diameter of the hole is minimal. The hole drilling method was carried out as per ASTM standard E 83799. Three HBM rosette strain gauges were attached as shown in Figure 3(a) and a $2 \mathrm{~mm}$ diameter hole was drilled at the centre of the hardfaced coating from the top, by a pneumatic drilling machine. The angle between the gauges $a$ and $b$ as well as that between the gauges $b$ and $c$ was $135^{\circ}$, as shown in Figure 3(b) [15]. Residual strains were measured at every $0.1 \mathrm{~mm}$ increment of depth up to the depth of $2 \mathrm{~mm}$ along the same hole. In the same manner, another $2 \mathrm{~mm}$ diameter hole was drilled $5 \mathrm{~mm}$ from the fusion line (in steel), after attaching the strain gauges. Strain gauge readings were noted, and Figures 5(a) and 5(b) were plotted.

\section{Stress Analysis}

The hardfaced circular grid plate model had been meshed, using an 8-node 2D axisymmetric coupled temperature displacement element (CAX8RT). A total of 13729 nodes and 4472 elements were created. By revolving a plane cross section about an axis, a body of revolution was generated. It was mentioned in cylindrical polar coordinates $r, z$, and $\theta$. To evaluate the residual stress using FEA, an elastoplastic analysis was carried out, and the results were compared to those obtained by hole drilling method. In this paper, the commercial FE modelling package ABAQUS was used to find the residual stress, which arises due to the thermal cycling of the hardfaced circular gird plate. A sequentially coupled temperature displacement analysis was conducted, using ABAQUS/Standard. To predict accurate results, temperaturedependent material properties are important. To perform 


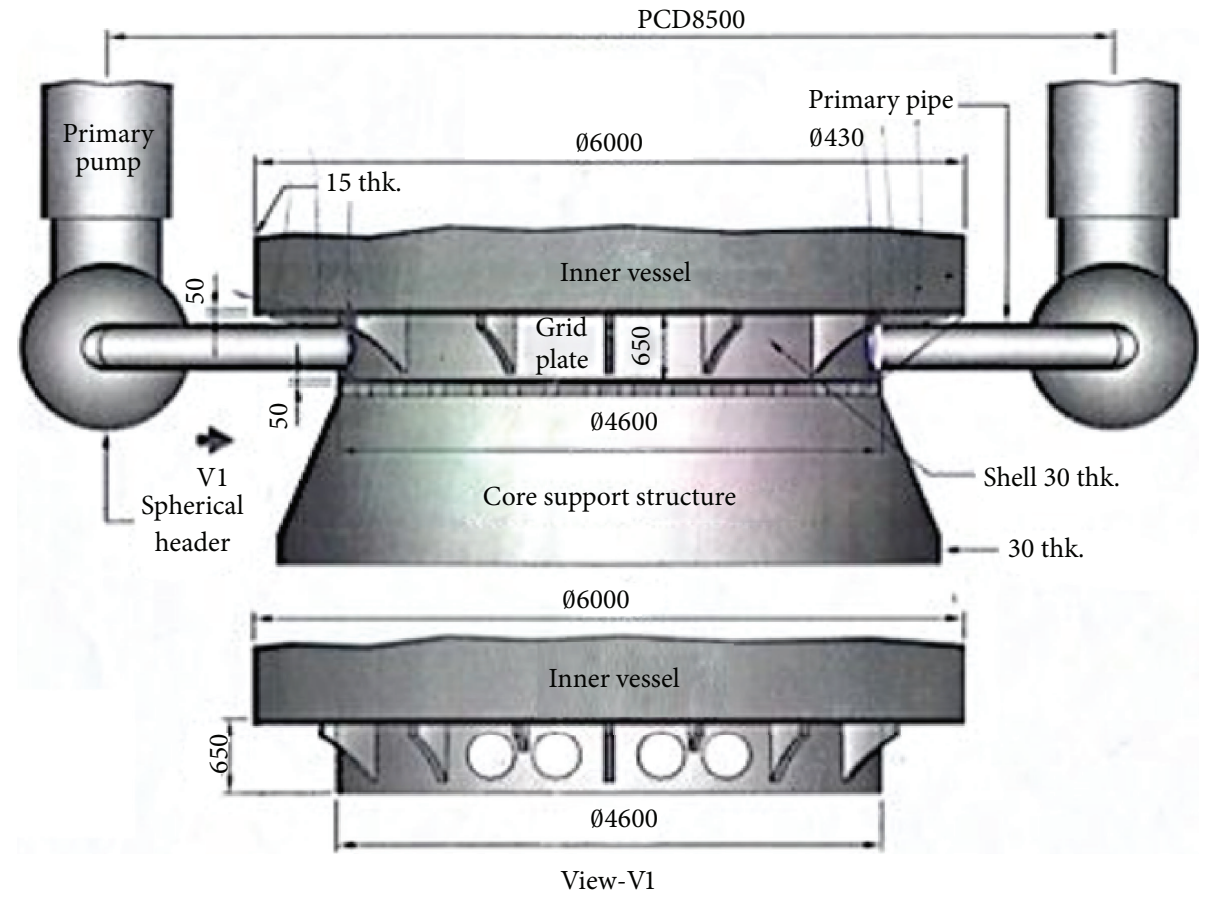

(a)

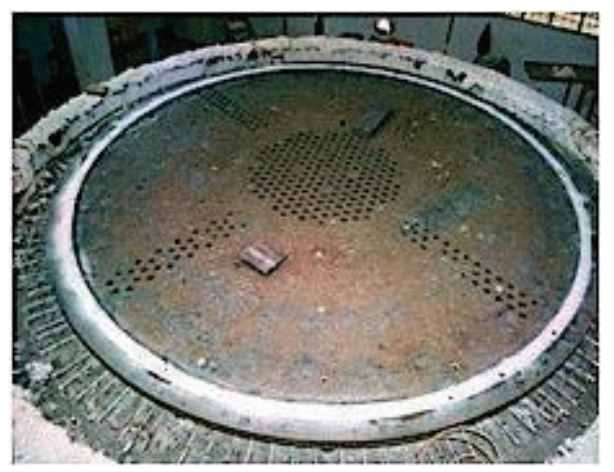

(b)

FIGURE 1: (a) Grid plate-primary pipe-CSS assembly. (b) Bottom of the grid plate assembly after hardfacing.

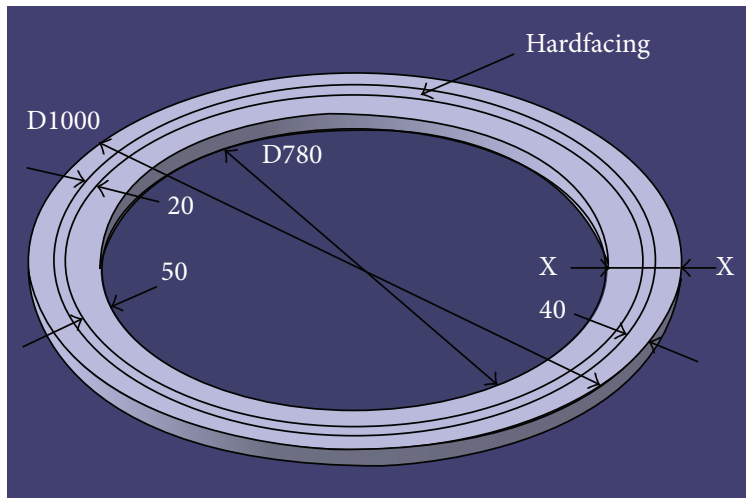

(a)

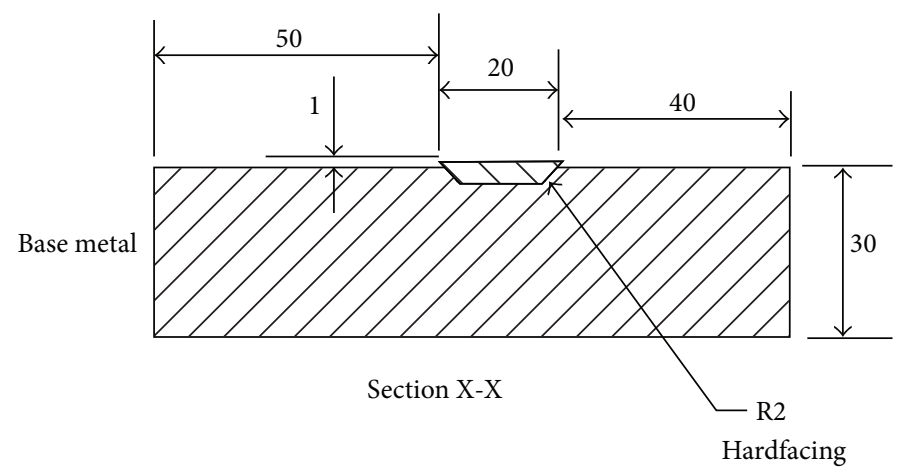

(b)

FIGURE 2: Geometry of the model used in the analysis. 


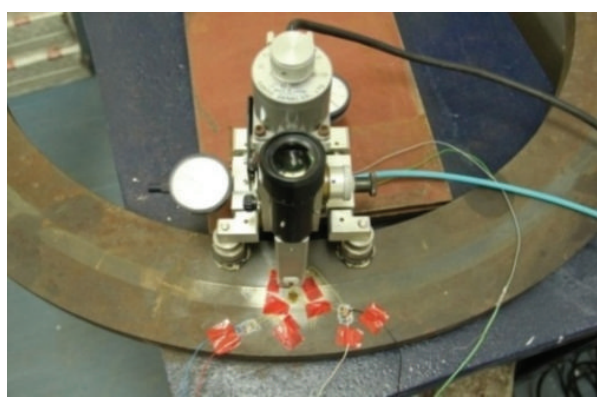

(a)

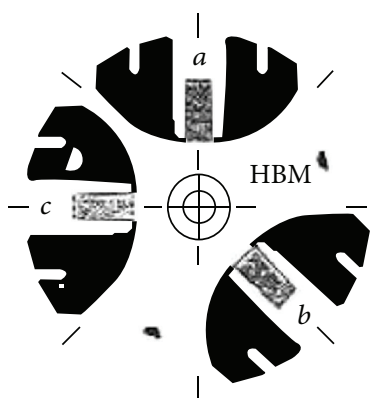

(b)

FIGURE 3: (a) Strain gauge rosette attached on the hardfaced surface. (b) Strain gauge rosette used.

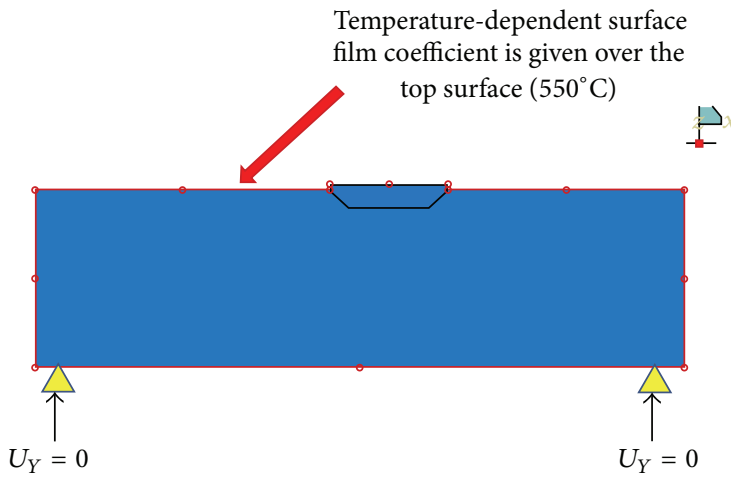

(a)

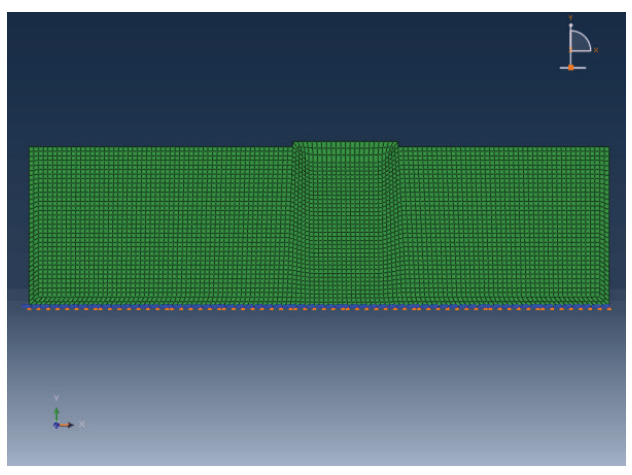

(b)

FIgURE 4: (a) Boundary conditions. (b) Meshed model.

elastoplastic analysis, it is necessary to give the plastic strain properties.

Boundary Conditions. The model was constrained along the bottom of the grid plate, as shown in Figure 4(a). The grid plate with hardfacing was subjected to thermal cycling. The thermal cycle was applied as shown in Figure 4(a). Since Figure 4(a) is a plane cross section of the axisymmetric model of the grid plate, the top surface was heated from room temperature to $550^{\circ} \mathrm{C}$ isothermally by placing a heat source of $550^{\circ} \mathrm{C}$. The initial temperature of the hardfaced circular grid plate was $30^{\circ} \mathrm{C}$. By exactly defining the predefined field in the load module, the initial condition of the hardfaced circular grid plate could be created. A combined convection and radiation film coefficient was used in this analysis as the convection film coefficient.

The temperature-dependent total convective film coefficient is shown in following equation:

$$
H_{\text {tot }}=2.41 * 10^{-3} \varepsilon T^{1.61} \quad[25] .
$$

From the above equation, temperature-dependent convective film coefficient was determined. Here, $H_{\text {tot }}$ is known as the convective heat transfer coefficient. $T$ is the temperature of the plate. $\varepsilon$ is the emissivity. For stainless steel $316 \mathrm{~L}(\mathrm{~N}) \mathrm{SS}$, $\varepsilon=0.64$ and for nickel based alloy colmonoy $\varepsilon=0.59$. The temperature-dependent convective film coefficients were applied over the outer surface of the hardfaced circular grid plate.

The temperature-dependent material properties of austenitic steel and colmonoy are given in Tables 1 and 2, respectively. The meshed model of the plate is shown in Figure 4(b).

\section{Results and Discussion}

The principal residual stresses obtained by the hole drilling method in colmonoy and base metal, after giving the thermal cycling same as that in the analysis, are shown in Figures 5(a) and 5(b), respectively. In the coating shown in Figure 5(a), it is seen that, up to around 0.2 to $0.3 \mathrm{~mm}$ depth, the three strain gauges indicate minimum order of strain around $80 \mu \mathrm{m} / \mathrm{m}$. From $0.3 \mathrm{~mm}$ depth, there is a progressive rise in the relieved strain up to 0.9 to $1 \mathrm{~mm}$ depth. However, three locations of the strain gauge record varying order of strains of 350, 450, and $550 \mu \mathrm{m} / \mathrm{m}$ for gauges $c, b$, and $a$, respectively, indicating directional stressing or cooling of the material during thermal cycling.

In case of steel shown in Figure 5(b), the residual strain (stress) tends to change up to $1 \mathrm{~mm}$ depth below the surface above which it sets in. Strain gauge location $a$ shows a maximum compressive strain drooping from 0 to $160 \mu \mathrm{m} / \mathrm{m}$ over a depth of around $1 \mathrm{~mm}$. However, strain gauge $b$ indicates the minimum order of strain, However, strain gauge 
TABLE 1: Temperature-dependent material properties of austenitic steel.

\begin{tabular}{|c|c|c|c|c|c|c|c|}
\hline Temp. (K) & $\begin{array}{l}\text { Specific heat } \\
(\mathrm{J} / \mathrm{kgK})\end{array}$ & $\begin{array}{l}\text { Conductivity } \\
(\mathrm{W} / \mathrm{mK})\end{array}$ & $\begin{array}{l}\text { Density } \\
\left(\mathrm{kg} / \mathrm{m}^{3}\right)\end{array}$ & $\begin{array}{l}\text { Yield stress } \\
\quad(\mathrm{MPa})\end{array}$ & $\begin{array}{l}\text { Thermal expansion } \\
\text { coefficient }\left(10^{-5} / \mathrm{K}\right)\end{array}$ & $\begin{array}{l}\text { Young's } \\
\text { modulus } \\
(\mathrm{GPa})\end{array}$ & Poisson ratio \\
\hline 300 & 492 & 15.0 & 7900 & 230 & 1.9 & 200 & 0.278 \\
\hline 473 & 515 & 17.5 & 7830 & 184 & 1.9 & 185 & 0.288 \\
\hline 673 & 563 & 20.0 & 7750 & 132 & 1.9 & 170 & 0.298 \\
\hline 873 & 581 & 22.5 & 7660 & 105 & 1.9 & 153 & 0.313 \\
\hline 1073 & 609 & 25.5 & 7560 & 77 & 1.9 & 135 & 0.327 \\
\hline 1273 & 631 & 28.3 & 7370 & 50 & 1.9 & 96 & 0.342 \\
\hline 1473 & 654 & 31.1 & 7320 & 10 & 1.9 & 50 & 0.350 \\
\hline 1613 & 669 & 33.1 & 7300 & 10 & 1.9 & 10 & 0.351 \\
\hline 1663 & 675 & 66.2 & 7270 & 10 & 1.9 & 10 & 0.353 \\
\hline
\end{tabular}

TABLE 2: Temperature-dependent material properties of colmonoy.

\begin{tabular}{|c|c|c|c|c|c|c|c|}
\hline Temp. (K) & $\begin{array}{l}\text { Specific heat } \\
(\mathrm{J} / \mathrm{kgK})\end{array}$ & $\begin{array}{l}\text { Conductivity } \\
(\mathrm{W} / \mathrm{mK})\end{array}$ & $\begin{array}{l}\text { Density } \\
\left(\mathrm{kg} / \mathrm{m}^{3}\right)\end{array}$ & $\begin{array}{l}\text { Yield stress } \\
(\mathrm{MPa})\end{array}$ & $\begin{array}{l}\text { Thermal expansion } \\
\text { coefficient }\left(10^{-5} / \mathrm{K}\right)\end{array}$ & $\begin{array}{c}\text { Young's } \\
\text { modulus (GPa) }\end{array}$ & Poisson ratio \\
\hline 300 & 475 & 10.5 & 7880 & 449 & 1.33 & 194 & 0.3 \\
\hline 473 & 525 & 13.5 & 7830 & 390 & 1.33 & 182 & 0.3 \\
\hline 673 & 553 & 16.6 & 7760 & 356 & 1.33 & 172 & 0.3 \\
\hline 873 & 597 & 20.4 & 7690 & 339 & 1.33 & 169 & 0.3 \\
\hline 1073 & 626 & 24.0 & 7640 & 305 & 1.33 & 136 & 0.3 \\
\hline 1273 & 659 & 28.7 & 7610 & 274 & 1.33 & 87 & 0.3 \\
\hline 1313 & 665 & 29.2 & 7570 & 265 & 1.33 & 70 & 0.3 \\
\hline
\end{tabular}

$b$ indicates the minimum order of strain, that too tensile in nature with the steady state value of $20-25 \mu \mathrm{m} / \mathrm{m}$. The strain gauge location $c$ indicates the progressive rise in tensile strain up to $1 \mathrm{~mm}$ to the value of $110 \mu \mathrm{m} / \mathrm{m}$ above which it sets in. Unlike the case of coating experiencing nearly hydrostatic compressive residual strain, the steel experiences bimodal strain.

From Figure 5(a), it is understood that the residual stress increases up to a depth of $1 \mathrm{~mm}$ from the surface, and thereafter it remains almost constant. This means that the inner surface (up to the depth of $1 \mathrm{~mm}$ ) cools more rapidly compared to the outer surface. While heating, the expansion of steel is more than that of the coating because $316 \mathrm{~L}(\mathrm{~N}) \mathrm{SS}$ has 1.5 times higher coefficient of thermal expansion than colmonoy (for $316 \mathrm{~L}(\mathrm{~N})$ SS $1.9 \times 10^{-5} / \mathrm{K}$, for colmonoy 1.3 $\left.\times 10^{-5} / \mathrm{K}\right)$. Therefore, steel is subjected to compressive stress and the coating is subjected to tensile stress during heating as they are in contact with each other. Since cooling is the last phase of the thermal cycle, the coating is subjected to principal residual stresses of compressive nature along the circumferential and radial directions.

Figure 5(b) shows the graph in which the residual stress in steel ( $5 \mathrm{~mm}$ from fusion line) increases up to a depth of $1 \mathrm{~mm}$, and thereafter it remains constant. Contrary to colmonoy, the steel is subjected to tensile stress circumferentially after cooling, due to the higher coefficient of thermal expansion than colmonoy. Similar to colmonoy, the steel is subjected to compressive stress radially, as the annular colmonoy coating is subjected to compressive stress towards the centre of the grid plate model. Since the elastoplastic analysis is nonlinear, first of all, elastic analysis is carried out under steady state condition as it is linear. In the case of the elastic analysis, the residual stresses vanished at the end.

Since colmonoy is brittle in nature, maximum principal stress theory is used. According to maximum principal stress theory, failure occurs when the maximum principal stress reaches the ultimate stress of the material.

From Figure 5(a), since $\sigma_{\min }$ is numerically greater than $\sigma_{\max }$ for colmonoy, $\sigma_{\min }$ is considered as the maximum principal residual stress as per the theory. Since $\sigma_{\min }=$ $413 \mathrm{MPa}$ which is less than the ultimate stress of the colmonoy ( $465 \mathrm{MPa})$, it is evident that failure did not take place in the coating and the coating is safe.

Since steel is ductile in nature, von Mises theory is used.

From Figure 5(b), since $\sigma_{\max }=114 \mathrm{MPa}$ and $\sigma_{\min }=$ $-61 \mathrm{MPa}$ as measured in $316 \mathrm{~L}(\mathrm{~N})$ SS by the hole drilling method, the von Mises residual stress in $316 \mathrm{~L}(\mathrm{~N})$ SS is calculated as given below:

$$
\begin{aligned}
\sigma_{v m} & =\sqrt{\left(\sigma_{\max }^{2}+\sigma_{\min }^{2}-\sigma_{\max } \sigma_{\min }\right)} \\
& =\sqrt{\left(114^{2}+(-61)^{2}-114 \times(-61)\right)}=154 \mathrm{MPa} .
\end{aligned}
$$

Since the von Mises residual stress obtained by both the experimental methods in $316 \mathrm{~L}(\mathrm{~N})$ SS is less than the yielding stress of $316 \mathrm{~L}(\mathrm{~N}) \mathrm{SS}(230 \mathrm{MPa})$, the steel portion of the grid plate is also safe due to thermal cycling. 


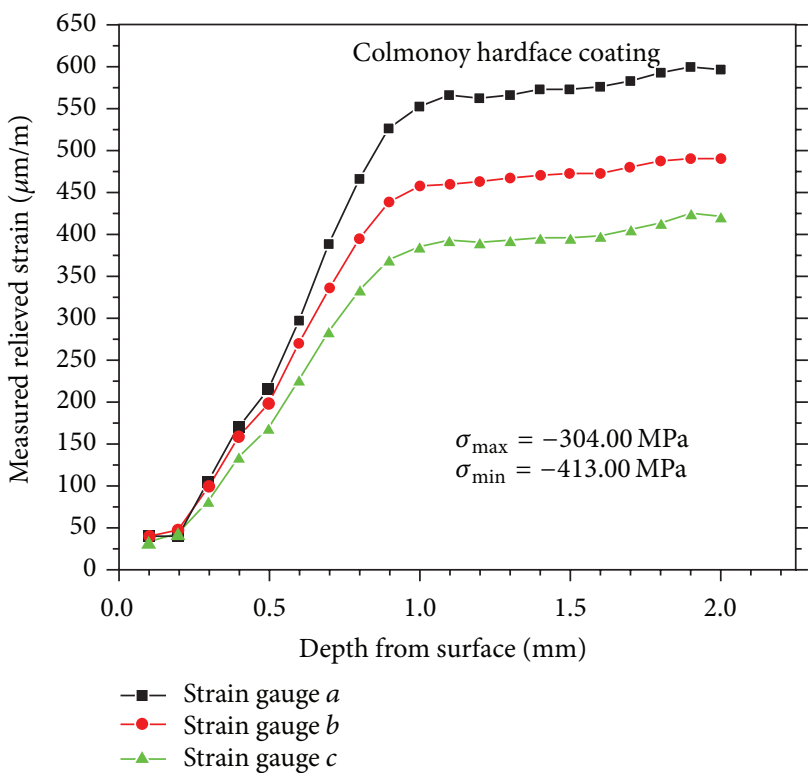

(a)

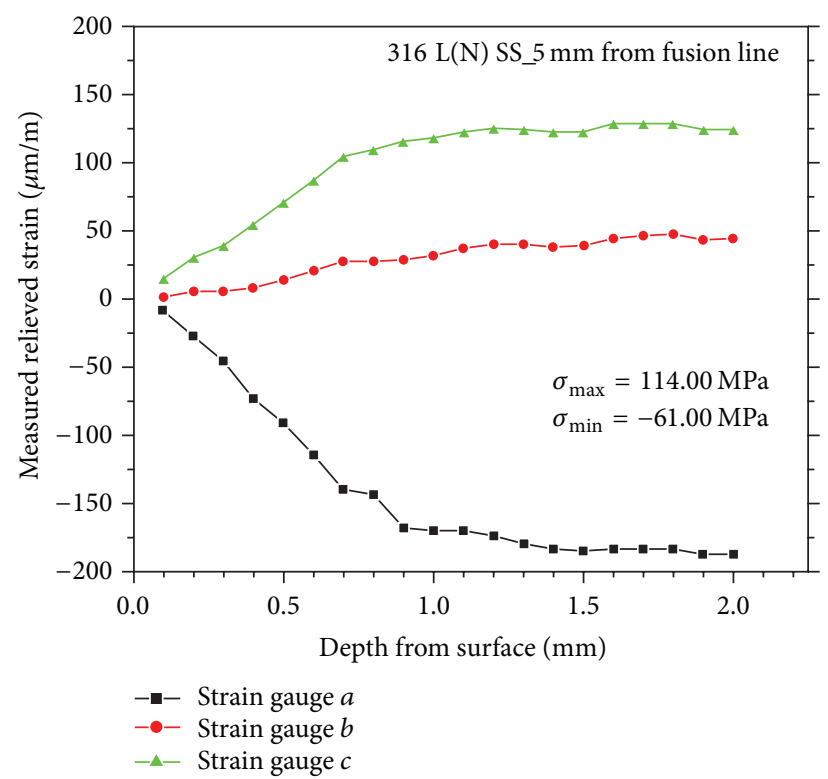

(b)

FIGURE 5: (a) Measured relieved strain versus depth from the surface in the colmonoy region. (b) Measured relieved strain versus depth from the surface in the base metal region.

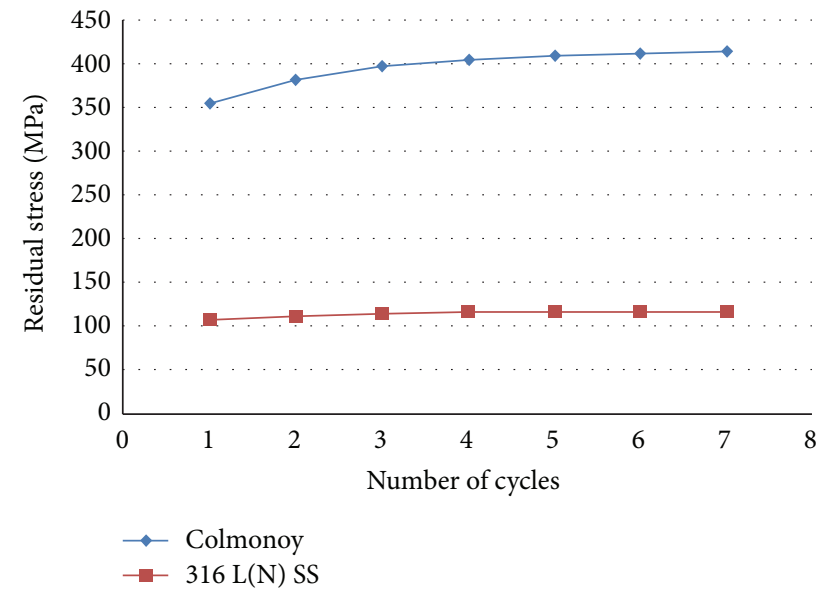

Figure 6: Convergence study of residual stress.

\section{Elastoplastic Analysis}

Though one thermal cycling process was given experimentally, the numerical results of the first cycle will not give the residual stress exactly [25]. The results have to converge to get the exact values. It took 7 cycles for convergence and the values of residual stresses for colmonoy and 316 L(N) SS in each cycle in those locations are given in Figure 6.

Figure 7 shows the distribution of residual stress at the end of 3rd cycle.

For colmonoy, thought the von Mises criterion is not applicable, the von Mises residual stress has to be calculated based on experimental results, for comparing with the numerical values. Since $\sigma_{\max }=-304 \mathrm{MPa}$ and $\sigma_{\min }=$

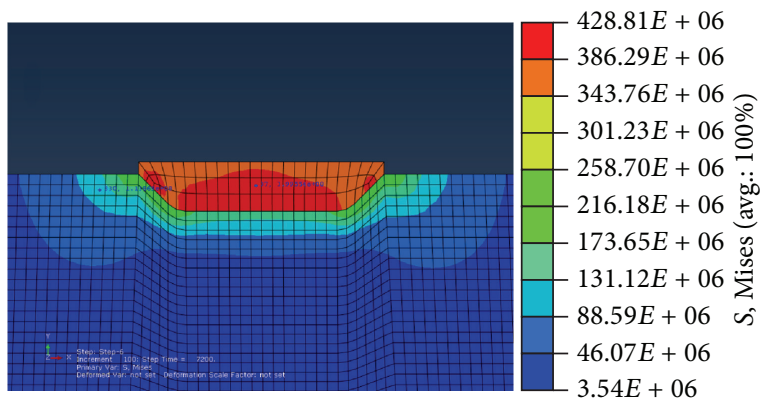

FIGURE 7: von Mises residual stress at the end of 3 thermal cycles.

$-413 \mathrm{MPa}$ as measured by hole drilling method in colmonoy, the von Mises residual stress in colmonoy is calculated as given below:

$$
\begin{aligned}
\sigma_{v m} & =\sqrt{\left(\sigma_{\max }^{2}+\sigma_{\min }^{2}-\sigma_{\max } \sigma_{\min }\right)} \\
& =\sqrt{(-304)^{2}+(-413)^{2}-(-304) \times(-413)} \\
& =370 \mathrm{MPa} .
\end{aligned}
$$

By the elastoplastic analysis, the von Mises residual stress was found to be $416.5 \mathrm{MPa}$ at $1 \mathrm{~mm}$ below the top surface of the colmonoy shown in Figure 8. This is close to the experimental value of $370 \mathrm{MPa}$.

For steel, by the elastoplastic analysis, the von Mises residual stress was found to be $116.2 \mathrm{MPa}$ at $5 \mathrm{~mm}$ from the fusion line. The numerical value varies by $11 \%$ from the experimental value found at the same location. 


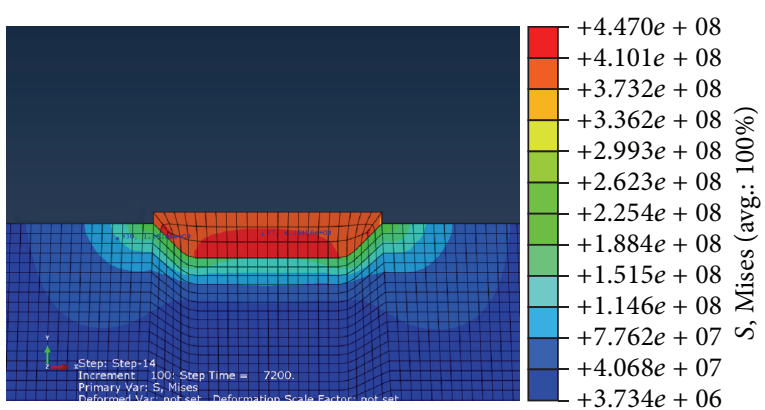

FIGURE 8: von Mises residual stress at the end of 7 thermal cycles, after convergence.

\section{Conclusions}

In this paper, the circular grid plate made of $316 \mathrm{~L}(\mathrm{~N})$ SS deposited with hardfacing colmonoy, used in nuclear reactors, and subjected to thermal cycling is analysed for residual stress using the hole drilling method and validated by the finite element analysis.

(i) Under elastoplastic analysis, the von Mises residual stress did not vanish at the end of the cycle due to the presence of plastic strain.

(ii) For the coating which is brittle in nature, maximum principal stress theory is applicable. Since the experimental value of the maximum principal residual stress (413 $\mathrm{MPa}$ ) is lower than the ultimate stress $(465 \mathrm{MPa})$ of the material, failure did not take place even when the thermal cycling reaches its maximum value of $550^{\circ} \mathrm{C}$. Therefore, the coating is safe due to thermal cycling.

(iii) For the steel which is ductile in nature, von Mises stress theory is applicable. Since the determined value of the von Mises residual stress (154 MPa) from the experimental principal stresses is lower than the yield stress $(230 \mathrm{MPa})$ of the material, failure did not take place even when the thermal cycling reaches its maximum value of $550^{\circ} \mathrm{C}$. Therefore, the steel portion of the grid plate is also safe due to thermal cycling.

(iv) In the case of colmonoy, the residual stress is compressive in nature along the circumferential direction, whereas in the case of steel it is tensile in nature as the coefficient of thermal expansion of colmonoy is lower than that of steel.

(v) In the case of both steel and colmonoy, the residual stresses are compressive in nature along the radial direction

(vi) For the coating, from the elastoplastic analysis, the numerical value of the von Mises residual stress differs from that of the determined value from the experimental results of principal stresses by only 11$12 \%$.

(vii) For the steel, from the elastoplastic analysis, the numerical value of the von Mises residual stress differs from that of the determined value from the experimental results of principal stresses by only $11 \%$.

(viii) The experimental and numerical simulations performed in conjunction with physical, material, and mechanical data generation have provided high confidence on the effects of the residual stresses due to thermal cycling for the safety of the grid plate applications in a pool type sodium-cooled fast reactor.

\section{Competing Interests}

The authors declare that they have no competing interests.

\section{Acknowledgments}

The authors are thankful to Dr. Shaju K. Albert, Head, MTD, and Mr. R. Sureshkumar, Head, SML, of IGCAR, Kalpakkam, for their help while carrying out this work.

\section{References}

[1] P. Vasantharaja, V. Maduarimuthu, M. Vasudevan, and P. Palanichamy, "Assessment of residual stresses and distortion in stainless steel weld joints," Materials and Manufacturing Processes, vol. 27, no. 12, pp. 1376-1381, 2012.

[2] S. K. Ray, V. Shankar, V. Balasubramanian, Sethi, and S. L. Mannan, "Heat treatment of austenitic stainless steel components," Transactions of The Indian Institute of Materials, pp. 249-251, 2003.

[3] M. Selvaraj, V. Murali, and S. R. Koteswara Rao, "Mechanism of weld formation during friction stir welding of aluminum alloy," Materials and Manufacturing Processes, vol. 28, no. 5, pp. 595600, 2013.

[4] A. K. Bhaduri, R. India, B. P. S. Rao et al., Hardfacing of NSSS Components of PFBR, Transactions of The Indian Institute of Materials, 2003.

[5] S. Murugan, P. V. Kumar, T. P. S. Gill, B. Raj, and M. S. C. Bose, "Numerical modelling and experimental determination of temperature distribution during manual metal arc welding," Science and Technology of Welding and Joining, vol. 4, no. 6, pp. 357-364, 1999.

[6] A. R. Kohandehghan, S. Serajzadeh, and A. H. Kokabi, "A study on residual stresses in gas tungsten arc welding of AA5251," Materials and Manufacturing Processes, vol. 25, no. 11, pp. 12421250, 2010.

[7] H. C. Dey, A. K. Bhaduri, S. Mahadevan et al., "Residual stress distribution in hardfaced austenitic stainless steel sleeves," Transactions of the Indian Institute of Metals, vol. 57, no. 3, pp. 271-276, 2004.

[8] P. Chellapandi, S. C. Chetal, and B. Raj, "Investigation on buckling of FBR vessels under seismic loadings with fluid structure interactions," Nuclear Engineering and Design, vol. 238, no. 12, pp. 3208-3217, 2008.

[9] M. K. Park, R. A. Sindhu, S. J. Lee, B. A. Zai, and H. Mehboob, "A residual stress evaluation in laser welded lap joint with hole drilling method," International Journal of Precision Engineering and Manufacturing, vol. 10, no. 5, pp. 89-95, 2009.

[10] M. Sedighi and M. Mahmoodi, "Residual stress, nanohardness, and microstructure changes in whirlwind milling of GCr15 
steel," Materials and Manufacturing Processes, vol. 28, pp. 85-90, 2013.

[11] U. Makoto, K. Jinya, N. Hiroyuki, and O. Kunio, "Evaluation of residual stress near the weld overlay cladding by welding and post-weld heat treatment," Welding International, vol. 28, no. 7, pp. 521-534, 2014.

[12] N. Murugan and R. Narayanan, "Finite element simulation of residual stresses and their measurement by contour method," Materials and Design, vol. 30, no. 6, pp. 2067-2071, 2009.

[13] A. A. Antonov and O. E. Kapustin, "Determination of maximum residual stresses in butt-welded joints in transmission pipelines," Welding International, vol. 25, no. 7, pp. 556-561, 2011.

[14] G. S. Schajer, "Advances in Hole-drilling residual stress measurements," Experimental Mechanics, vol. 50, no. 2, pp. 159-168, 2010.

[15] K. Nakacho, T. Ohta, N. Ogawa et al., "Measurement of welding residual stresses of reactor vessel by inherent strain method: measurement of residual stresses of pipe-plate penetration joint," Welding International, vol. 23, no. 6, pp. 439-449, 2009.

[16] A. K. Bhaduri, R. Indira, S. K. Albert, B. P. S. Rao, S. C. Jain, and S. Asokkumar, "Selection of hardfacing material for components of the Indian Prototype Fast Breeder Reactor," Journal of Nuclear Materials, vol. 334, no. 2-3, pp. 109-114, 2004.

[17] V. Balasubramanian, A. Lakshminarayanan, R. Varahamoorthy, and S. Babu, "Application of response surface methodolody to prediction of dilution in plasma transferred arc hardfacing of stainless steel on carbon steel," Journal of Iron and Steel Research International, vol. 16, no. 1, pp. 44-53, 2009.

[18] C. Sudha, P. Shankar, R. V. S. Rao, R. Thirumurugesan, M. Vijayalakshmi, and B. Raj, "Microchemical and microstructural studies in a PTA weld overlay of Ni-Cr-Si-B alloy on AISI 304L stainless steel," Surface and Coatings Technology, vol. 202, no. 10, pp. 2103-2112, 2008.

[19] J. H. Chang, C. P. Chang, J. M. Chou, R. I. Hsieh, and J. L. Lee, "Microstructure and bonding behavior on the interface of an induction-melted Ni-based alloy coating and AISI 4140 steel substrate," Surface and Coatings Technology, vol. 204, no. 20, pp. 3173-3181, 2010.

[20] D. Kesavan and M. Kamaraj, "The microstructure and high temperature wear performance of a nickel base hardfaced coating," Surface and Coatings Technology, vol. 204, no. 24, pp. 4034-4043, 2010.

[21] K. Gurumoorthy, M. Kamaraj, K. P. Rao, A. S. Rao, and S. Venugopal, "Microstructural aspects of plasma transferred arc surfaced Ni-based hardfacing alloy," Materials Science and Engineering A, vol. 456, no. 1-2, pp. 11-19, 2007.

[22] S. Balaguru, S. Kumar, V. Murali, and P. Chellapandi, “Thermo mechanical analysis of SS304 circular grid plate hard faced with colmonoy," Applied Mechanics and Materials, vol. 229-231, pp. 710-717, 2012.

[23] S. Balaguru, K. Deenadayalan, M. Vela, and P. Chellapandi, "Influence of welding speed over dilution for circular grid plate hardfaced with colmonoy-5," Applied Mechanics and Materials, vol. 565, pp. 53-58, 2014.

[24] S. Balaguru, V. Murali, and P. Chellapandi, "Effects of welding speeds on macro and micrstructures in hardfacing of colmonoy on on un-grooved and grooved $316 \mathrm{~L}(\mathrm{~N})$ SS base metal," International Journal Applied Engineering Research, vol. 10, pp. 25627-25631, 2015.

[25] K. Punitharani, N. Murugan, and S. M. Sivagami, "Finite element analysis of residual stresses and distortion in hard faced gate valve," Journal of Scientific and Industrial Research, vol. 69, no. 2, pp. 129-134, 2010. 

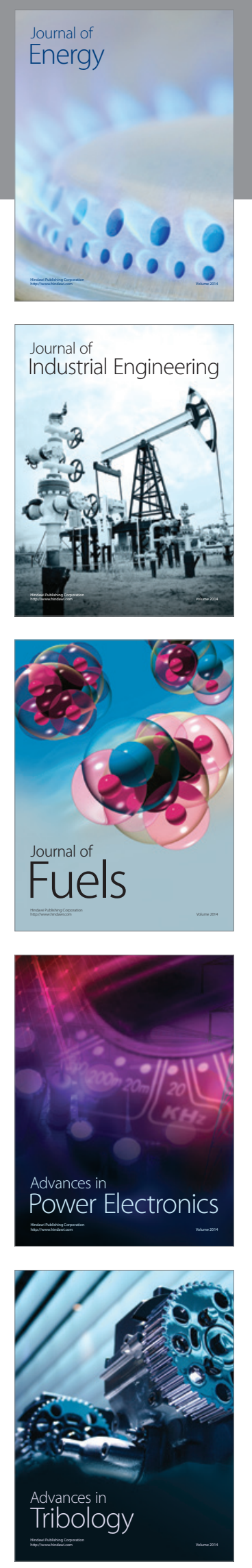
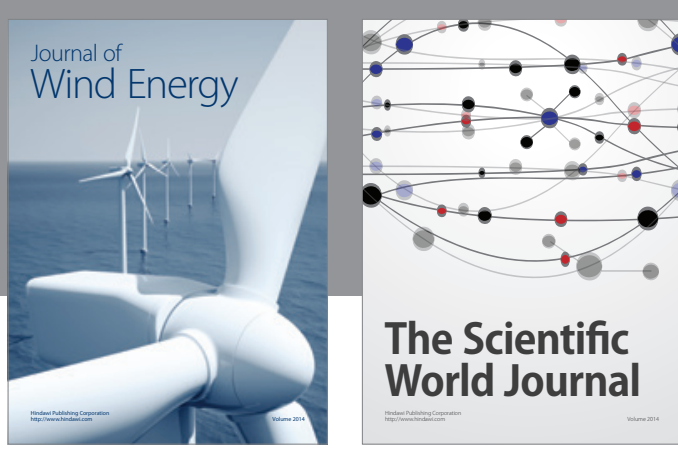

The Scientific World Journal
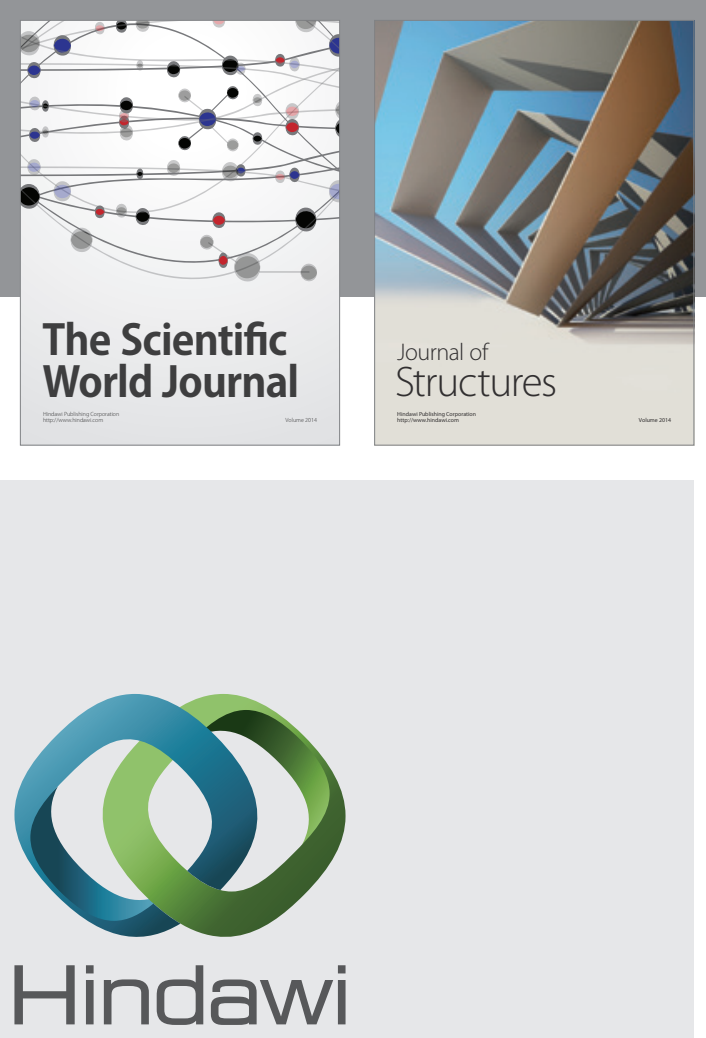

Submit your manuscripts at

http://www.hindawi.com
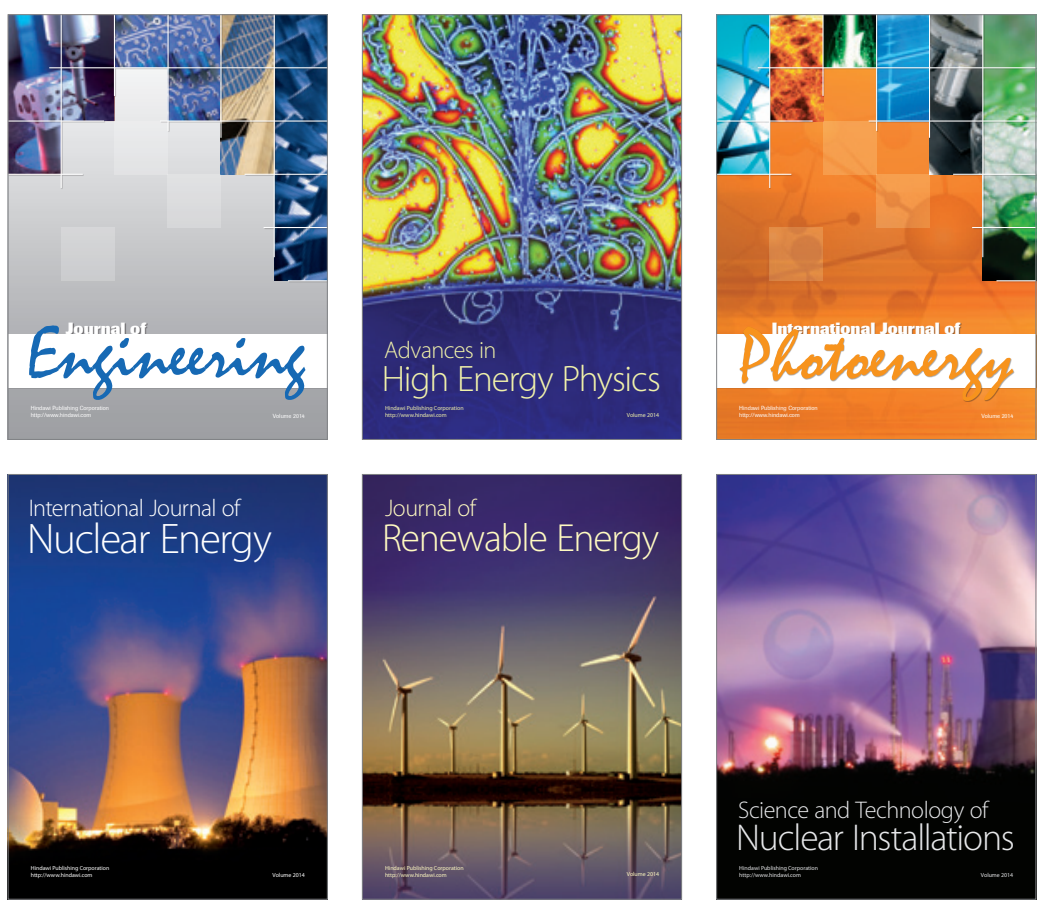
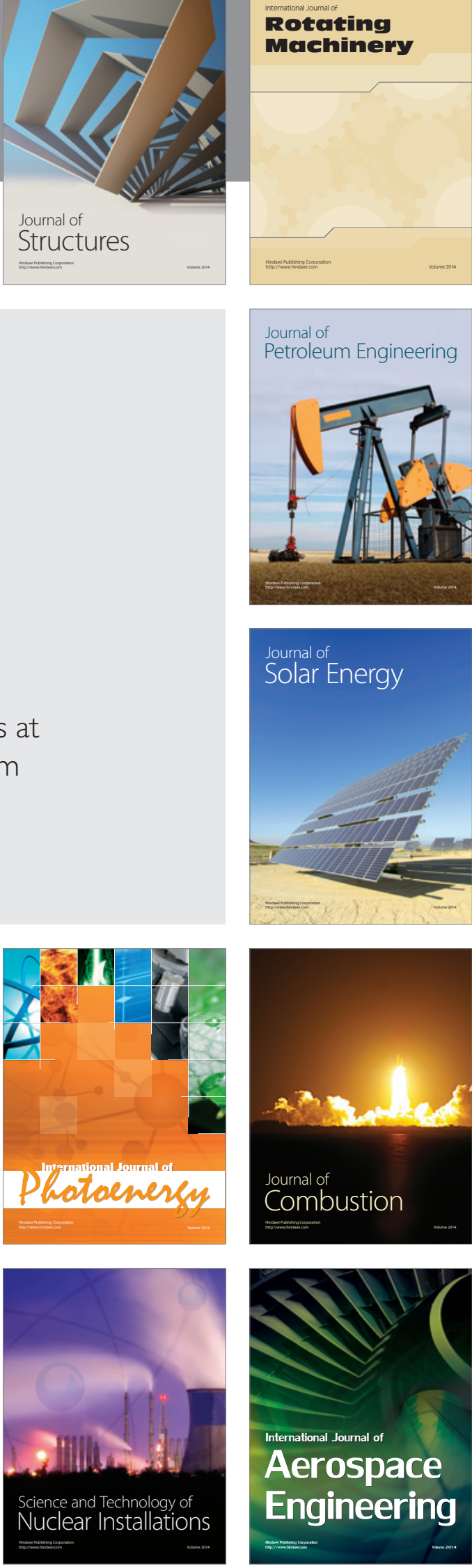